\title{
The role of psychological climate in facilitating employee adjustment during organizational change
}

\author{
Angela J. Martin \\ School of Management, University of Tasmania, Hobart, Australia \\ Elizabeth S. Jones \\ School of Psychology, Griffith University, Brisbane, Australia \\ Victor J. Callan \\ School of Business, University of Queensland, Brisbane, Australia
}

\begin{abstract}
The current research tested a theoretical model of employee adjustment during organizational change based on Lazarus and Folkman's (1984) cognitivephenomenological framework. The model hypothesized that psychological climate variables would act as coping resources and predict improved adjustment during change. Two variations of this model were tested using survey data from two different organizational samples: 779 public hospital employees and 877 public sector employees. Confirmatory factor analyses and structural equation analyses were conducted in order to evaluate the models. Results showed that employees whose perceptions of the organization and environment in which they were working (that is, psychological climate) were more positive, were more likely to appraise change favourably and report better adjustment in terms of higher job satisfaction, psychological well-being, and organizational commitment, and lower absenteeism and turnover intentions.
\end{abstract}

Effective management of the psychological transition of employees is integral in the achievement of successful organizational change (Bennett \& Durkin, 2000; St. Amour, 2001). Successful adjustment to change can result

Correspondence should be addressed to Dr Angela J. Martin, School of Management, University of Tasmania, Hobart, Australia. Email: Angela.Martin@utas.edu.au

The research reported in this article was supported by an Australian Research Council Strategic Partners Industry, Research and Training grant held by V. Callan, C. Gallois, E. Jones, and P. Bordia. Financial support from the Department of Management and the School of Applied Psychology at Griffith University is also acknowledged. In addition, many thanks are due to Stephen Cox for his assistance with the structural equation analyses and Bernadette Watson for her assistance with data collection.

(C) 2005 Psychology Press Ltd

http://www.tandf.co.uk/journals/pp/1359432X.html

DOI: $10.1080 / 13594320500141228$ 
in higher levels of enthusiasm for future change, providing opportunities for learning and growth. Alternatively, poor adjustment to change is characterized by feelings of threat, uncertainty, frustration, alienation, and anxiety, particularly in relation to issues of job security, status, work tasks, co-worker relations, and reporting relationships (Ashford, 1988). Organizational change is a major source of workplace stress and is associated with a wide range of negative behavioural, psychological, and physiological outcomes (Ashford, 1988; Lokk \& Arnetz, 1997; Roney \& Cooper, 1997; Schabracq \& Cooper 1998). A lack of attention to employees' psychological responses to organizational change is implicated in the failure of change programs (Kotter, 1995) and other important organizational outcomes such as impaired productivity, and increased levels of absenteeism, industrial dispute, and turnover (Eby, Adams, Russell, \& Gaby, 2000; Mack, Nelson, \& Quick, 1998).

Little research attention has been paid to the development and testing of theory-based models of the psychological experiences of employees during organizational change. Such knowledge has important implications for improved change management. The present research extended Lazarus and Folkman's (1984) seminal work on stress and coping theory by examining how key dimensions of psychological climate relate to employee appraisals of, and levels of adjustment during, a program of planned organizational change.

The cognitive-phenomenological theory of stress and coping posits that adjustment during stressful events is a process that commences with the cognitive and affective appraisal of the event (Lazarus, 1990; Lazarus \& Folkman, 1984). The effects of these perceptions on the individual's level of well-being are determined by the effectiveness of the coping strategies they enact in order to deal with the event. Both appraisal and coping are influenced by the personal and environmental resources that the individual has access to (Lazarus \& Folkman, 1984). The study of personal coping resources, which focuses on individual differences such as personality and lifestyle factors, has dominated stress research. Less attention, however, has been paid to the role of environmental and organizational coping resources, despite the fact that several authors have argued that organizational determinants of perceived stress and work attitudes have a broader span of influence and are more readily altered than individual determinants (Burke, 1993; Eby et al., 2000; Fogarty et al., 1999; Lease, 1998; Reynolds \& Briner, 1994). The study of organizational coping resources is limited to the availability of social support in the workplace and its positive effects on employee stress responses (Kumari \& Sharma, 1990; Parks, 1990; Thoits, 1986). Terry, Callan, and Sartori (1996) have urged researchers to look beyond social support as an organizational determinant of adjustment. The perceived availability of social support from colleagues and superiors is an 
important dimension of the psychological climate in an organization. Hence, the construct of psychological climate is one potential area of focus for the identification of other workplace coping resources that might promote adjustment during organizational change.

A better understanding of climate should play a central role in the management of programs of planned organizational change, as it is argued that climate shapes employees' perceptions of the change process itself (Armenakis \& Bedeian, 1999; Eby et al., 2000; Pettigrew, 2000). In the present research, the role of environmental resources (characteristics of the individual's environment that assist in the process of adjustment during stressful situations) is investigated in relation to the construct of psychological climate in two organizations.

Psychological climate refers to the perceptual and experiential components of a reciprocal interaction between the organizational environment and the employee (Michela, Lukaszwski, \& Allegrante, 1995). It has been conceptualized as a construct "comprising an individual's psychologically meaningful representations of proximal organizational structures, processes and events" and as "a means of explaining an individual's motivational and affective reactions to change" (Parker et al., 2003, p. 390). It is important to note the distinction between psychological climate, a property of the individual, and organizational climate, a group-level construct obtained via the statistical measurement of the degree to which climate is shared by organizational members (Pettigrew, 2000; Schneider, 2000). The fact that there is little agreement about the specific dimensions that comprise the psychological climate construct must also be highlighted. As noted by Parker et al. (2003) employees' perceptions of virtually every aspect of their work environment have been included in psychological climate research and can be summarized under generic categories based on job, role, leader, work group, and organizational characteristics.

Not all elements of climate are equally potent in the degree to which they determine work attitudes (Parker et al., 2003). Accordingly, a number of different recommendations about how climate should be measured have been made. Glick (1985) argued that climate dimensions that are likely to be associated with the researcher's criterion variables should be selected. Schein (2000) noted that qualitative research can identify aspects of the climate that are salient to employees might be potentially stronger determinants of work attitudes when examined quantitatively. Payne (2000) also suggested that climate scales be designed in collaboration with members of the organization to increase their ecological and predictive validity. Recently, attention has also been directed towards the measurement of climate dimensions that apply to nonemployee stakeholder groups such as customers or other stakeholders (Burke, Borucki, \& Kaufman, 2002; Schneider, Bowen, Ehrhart, \& Holcombe, 2000). 
The present research attempted to integrate many of the above considerations in its operationalization of the climate construct and the dimensions of climate examined. Firstly, the role of a selected climate dimension considered salient by employees undergoing change in each of the two organizations studied was investigated. Thus, a unique climate dimension, theorized to be important in predicting employee perceptions of change, was determined through exploratory interviews in each organization. Secondly, a measure of the stakeholder dimension of climate was adapted for relevance in each of the organizations. Thirdly, due to the robust findings regarding social support and Michela and Burke's (2000) assertion that climate is influenced substantially by behaviours of the supervisor such as listening and providing feedback, supervisor support was also theorized as a generic dimension of climate in both organizations.

The present research proposed that the construct of psychological climate can be theoretically integrated with the cognitive-phenomenological perspective. As noted previously, psychological climate is concerned with an employee's perceptions, or meaningful representations, of the environment in which they are embedded. Similarly, the cognitive-phenomenological model is also focussed on the meaning derived from the interaction between the individual and their environment, and so the construct of psychological climate fits well into existing stress and adjustment models. Lazarus (2000, p. 665), for instance, recently described his theoretical approach as centred on the "relational meaning that an individual constructs from the person-environment relationship". He sees this relationship as "a result of appraisals of the confluence of the social and physical environment and personal goals, beliefs about self and world, and resources".

In his model, the construct of appraisal is central to understanding whether an individual will experience stress in a given situation. Primary appraisal represents a person's cognitive evaluation of how a situation or event will affect their level of well-being or how "stressful" they perceive it to be (Folkman, 1984). If a situation is considered to be potentially stressful, a secondary form of appraisal is activated consisting of two distinct judgements about the situation: perceived controllability and efficacy expectations (Terry, 1991). Control is a construct central to our understanding of psychological functioning and adjustment (Averill, 1973; Karasek, 1979; Terry \& Jimmieson, 1999). Perceived controllability represents the individual's judgement about whether they have any capacity to remove or modify the stressor. A person's efficacy expectancy, or their level of confidence in their ability to perform the behaviours necessary to deal with a stressor, is also a generally accepted determinant of adjustment (Bandura, 1982), particularly in situations such as career change and job insecurity (Judge, Thoresen, Pucik, \& Welbourne, 1999). It is important to 
note that control and self-efficacy are multifaceted constructs and are best measured in relation to a specific aspect of the work environment (Bandura, 1986; Ganster, 1985). In the present research, the appraisal constructsperceived stress, self-efficacy, and control-were measured specifically in relation to a program of organizational change.

The present research aimed to examine the role of psychological climate in predicting improved employee adjustment during organizational change. As described above, a central construct in the cognitive-phenomenological view of adjustment is appraisal of change. A positive psychological climate was conceptualized as a potential source of environmental coping resources that would facilitate positive change appraisal. These resources included: (1) a dimension of psychological climate identified as salient by employees undergoing change in each of the two organizations studied, (2) a measure of the stakeholder dimension of psychological climate relevant to each of the organizations, and (3) a generic dimension of psychological climate, the perceived level of supervisor support. It was proposed that each of the psychological climate variables would have direct effects on employee's appraisals of organizational change. Hence, the first hypothesis relates to the relationships predicted between climate and change appraisal variables (see conceptual model shown in Figure 1):

H1. Positive psychological climate ratings will be associated with more positive appraisals of change.

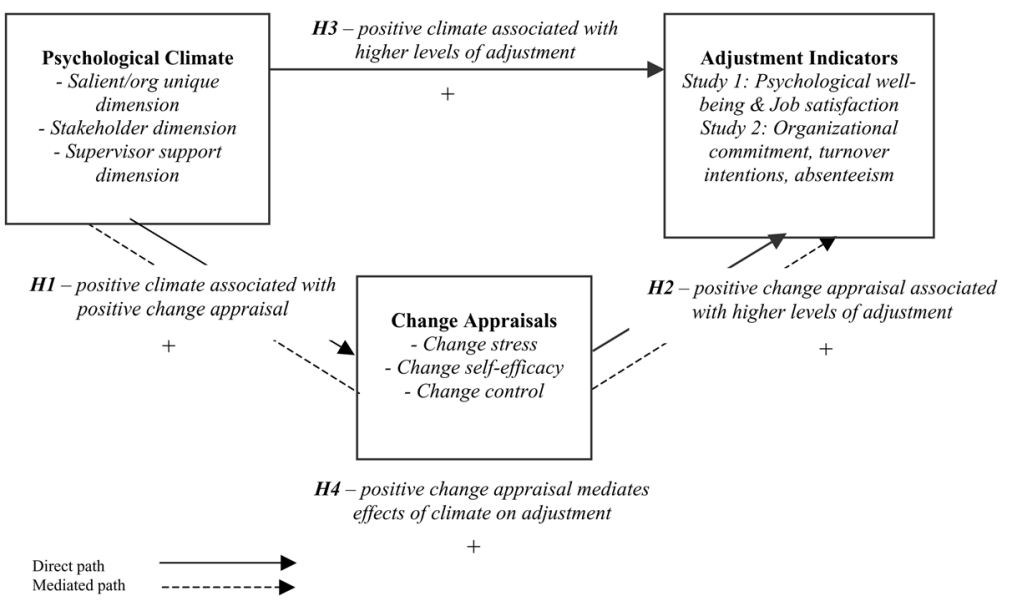

Figure 1. Conceptual model. 
The organizational change literature is underdeveloped in relation to the linkages between change appraisal and organizational outcomes (Pettigrew, Woodman, \& Cameron, 2001). It has been suggested that employee attitudes towards a pending change may have an impact on organizational commitment, absenteeism, and turnover (Eby et al., 2000; Mack et al., 1998; McManus, Russell, Freeman, \& Rohricht, 1995). Such outcomes have not been studied in relation to the cognitive-phenomenological framework of stress and adjustment. In the present research, a range of criterion variables were conceptualized as indicators of adjustment during change that included both psychological and behavioural indicators. Firstly, the research aimed to confirm previous findings related to the positive impact of favourable change appraisals on job satisfaction and psychological well-being (Terry et al., 1996). Hence, in the first organization studied, the model tested included measures of job satisfaction and psychological well-being as adjustment indicators. In the second organization studied, the model tested was modified (and theoretically extended) to include organizational commitment as an indicator of adjustment as well as other more distal outcomes of interest to organizations, such as turnover and absenteeism. Organizational commitment has been consistently identified as a key predictor of absenteeism and turnover intentions (Bennett \& Durkin, 2000; Lease, 1998). Hence, in the second organization, turnover intentions and absenteeism (not due to illness) were also specified as outcomes of adjustment.

As noted earlier, the literature has consistently identified that the experience of change has a major impact on employee effectiveness. Accordingly, in both studies, it was proposed that employees' psychological appraisals of the change process would have direct effects on the adjustment indicators. Hence, the second hypothesis relates to the relationships predicted between change appraisal and adjustment indicators:

H2. Positive appraisals of change will be associated with higher levels of the adjustment indicators.

Due to the evidence that psychological climate is a strong predictor of employee well-being, job satisfaction, and organizational commitment (Hemmingway \& Smith, 1999; Parker et al., 2003; Przygodda, Arentz, Quast, \& Kleinbeck, 1997; Schneider et al., 2000), direct effects of climate on these adjustment indicators were also expected:

H3. Positive psychological climate ratings will be associated with higher levels of the adjustment indicators.

A final hypothesis related to the appraisal construct was derived from the claim of Schaubroeck and Merritt (1997) that perceptions of demand, self- 
efficacy, and control are the key mediators of responses to stressful aspects of the work environment. Terry et al. (1996) found evidence that supported the mediating role of appraisal in the relationship between coping resources and adjustment indicators. Hence, in addition to the direct effects of climate on appraisal, appraisal on adjustment, and climate on adjustment, appraisal was also conceptualized as a mediating variable.

H4. The effects of the climate variables on the adjustment indicators will be mediated by the appraisal variables.

In summary, the present research tested a theoretical model of employee adjustment during organizational change (described above and illustrated in Figure 1). Theoretical predictions were tested in two variations of the model in two corresponding organizational samples. The samples were drawn from two large, public sector organizations that were experiencing extensive organizational change. ${ }^{1}$ Due to some variation in the measures used in each sample, the method of each of the two studies is presented separately. However, as the studies both aimed to evaluate the proposed theoretical structure of the model, the results and discussion sections for each of the studies are integrated.

\section{METHOD}

\section{Study 1}

Background. The first study was conducted in a large public hospital where employees were experiencing the introduction of large-scale organizational change. Hospital employees were part of the state public sector. Changes related to the redevelopment of the hospital site and included a move into a new hospital building, downsizing of staff prior to the move, a reduction in bed and patient numbers, and the implementation of multidisciplinary teams. The research was conducted when staff were in the midst of planning the changes including the design of the new building, the structure of new wards and working relationships, the merger of some divisions, and changes to work practices related to technological improvement. Downsizing was to be managed by natural attrition and no employees were at risk of losing their job. Driving the change process was a new CEO and a change management team. At the time of the survey, CEO forums, an internal newsletter, posters, and meetings between the CEO and divisions in

\footnotetext{
${ }^{1}$ These two organizations were industry partners in a large, government funded research project focused on organizational change.
} 
the hospital were being used as the major methods to communicate the nature and timetable of the changes. Management and staff were still actively planning and considering many of the changes, and weighing up the consequences of the new building for patient care and management. Significantly, the new building was seen by senior management as an opportunity to challenge existing job practices, to break down professional silos and power bases, and to create greater levels of teamwork and accountability. Thus, the survey being timed at 5-6 months into the change process was seen by management to be an excellent opportunity to determine the perceived success of the leadership, communication, and levels of consultation about the change process to date.

Procedure and sampling. All of the hospital staff were mailed a selfadministered, anonymous questionnaire asking them to participate in an "employee opinion survey" focusing on the changes they had been experiencing. The surveys were distributed with a cover letter from the $\mathrm{CEO}$ and the university research team outlining the procedures undertaken to assure confidentiality of responses. A postage-paid, return envelope was supplied.

A total of 779 surveys were returned for analysis - a $49 \%$ response rate. The sample consisted of $70 \%$ women and $30 \%$ men; $62 \%$ of participants were aged $20-40$ years and $38 \%$ were aged 41 and over. Thirty-seven per cent of participants had worked at the hospital for a period of 2 to 5 years and twenty-three per cent had worked there from 6 to 10 years. The occupational categories represented in the sample were clinicians $(9 \%)$, nurse clinicians $(46 \%)$, other health professionals $(13 \%)$, nonclinical staff $(25 \%)$, and others $(7 \%)$. Nonclinical staff were employed in a range of occupations directly or indirectly contributing to the care of patients through duties including cleaning, porterage, food service, laundry, and administration. Analysis of hospital statistics showed that the sample was representative of the composition of the organization's entire workforce on the basis of gender and occupational categories.

Measures. Participants provided background information on their gender, age, length of service, length of time in current position, and employment status (e.g., casual, full time, part time, contract, temporary). They also selected one of 12 staff classifications to describe their position (e.g., Nurse-Manager, Nurse-Clinician, Medical-Manager).

As discussed in the introduction, the measures of psychological climate included three dimensions, one considered salient in relation to the changes by employees of the organization studied (as recommended by Glick, 1985; Payne, 2000; Schein, 2000). As part of a larger research project, a series of 66 exploratory interviews with staff representative of the range of occupations 
and hierarchical levels within the hospital were conducted. Although a formal content analysis of the interview data is not within the scope of the current paper, the results informed the development of one of the climate measures. Most of the interview participants highlighted the importance of effective relationships between staff in planning and implementing change. Hence, employee relationships were theorized as the "salient" or "organization-specific" dimension of psychological climate for this study. The employee relationships construct was measured with three items developed from the interviews. These items asked staff to rate their level of agreement with statements about different aspects of working at the hospital (e.g., "Staff at my level treat each other with respect"; 1 = "strongly disagree" to 6 = "strongly agree"). The second climate measure related to the stakeholder dimension (see Burke et al., 2002; Schneider et al., 2000). In this organization, the need to deliver and maintain quality care to patients (despite changes to resources, relocation problems, and decreasing staffing levels) was of great concern. The stakeholder dimension was measured as perceived quality of patient care using four items developed for use in the survey in conjunction with hospital staff. Staff rated the extent of agreement with statements such as: "In my view, the hospital provides good quality patient care" ( $1=$ "strongly disagree" to $6=$ "strongly agree"). As these two measures were developed for use in the present research, no previous reliability data was available; however, as shown in Table 2, these measures demonstrated acceptable internal reliability. A third, generic measure of psychological climate was the supervisor support dimension measured using six items previously shown to be reliable by Terry et al. (1996). Participants rated how much they relied on their direct supervisor for various types of support (e.g., "How much can you rely on your direct supervisor to listen to you about work-related problems?" 1 = "not at all" to 4 = "very much").

Both primary and secondary appraisal was measured in relation to the changes experienced by employees. Perceived change-related stress was measured using four items asking participants to rate the change process on six point unipolar scales regarding the level of stress, disruption, difficulty, and extent of upset (e.g., "In general, the change process is": 1 = "not at all stressful" to $6=$ "extremely stressful"; $1=$ "not at all upsetting" to $6=$ "extremely upsetting"). Change control was measured with three items (e.g., "I will be able to influence the extent to which the changes will affect my job", 1 = "strongly disagree" to 5 = "strongly agree"). One item was reversescored: "I have no control over the extent to which the changes will affect my job". Change self-efficacy, or the extent to which participants felt they could perform the behaviours required to deal with the changes was assessed with four items (e.g., "I am confident in my ability to deal with the planned structural changes", $1=$ "strongly disagree" to $5=$ "strongly agree"). One item was reverse scored: "I have reason to believe I will not perform well in my 
job following the introduction of planned changes". Each of the appraisal measures was previously shown to be reliable by Terry et al. (1996).

Employee adjustment during change was measured using two indicators: job satisfaction and psychological well-being. Job satisfaction was assessed with five items using Caplan, Cobb, French, van Harrison, and Pinneau's (1975) scale assessing generalized levels of job satisfaction (e.g., "All things considered, how satisfied are you with your job?; 1 = "very dissatisfied" to $5=$ "very satisfied"). Psychological well-being was measured with a six-item subscale of Goldberg's (1972) psychological symptoms scale of the General Health Questionnaire (GHQ-12). Participants were asked to estimate how often they experienced six different negative psychological health symptoms (e.g., "Felt constantly under strain", $1=$ "not at all" to $4=$ "much more than usual"). The scores on these items were reversed to provide an assessment of psychological well-being.

The model tested in Study 1 predicted that employees with more positive perceptions of the psychological climate (relations between staff, quality of patient care, and levels of social support from their direct supervisor) would report more positive change appraisals (lower change stress and higher change control and self-efficacy), and higher levels of adjustment (psychological well-being and job satisfaction). In addition, it was expected that the effects of climate-based coping resources upon employee well-being and job satisfaction would be mediated by how positively employees appraised the changes (perceived change stress, self-efficacy, and control).

\section{Study 2}

Background. The second study was conducted in a large, public sector organization. Again, employees operated as part of the state public sector. The organization had undergone significant change and restructuring, including a demerger with another state government organization that they had merged with some 3 years previously. Many staff had changed locations and roles and were being asked to reidentify with their previous organizational structure and culture. The research took place as the final stages of the change program were being implemented. This provides a contrast with the stage of change investigated in Study 1, where changes were being planned and introduced. When the survey was conducted, nearly all of the restructuring was complete, and the other parts of the department were now reestablished in a new department in a separate building. The challenges being dealt with at the time of the survey were still considerable, including a change in funding that impacted upon services, a new CEO with a clear change agenda, and within this a redefinition and debate about the core mission and strategy of the enterprise. Staff communication and 
consultation about the impact of such changes was undertaken through CEO briefings, newsletters, and forums to measure staff concerns about the impact and direction of future changes.

Procedure and sampling. A self-administered, anonymous questionnaire was mailed to staff with a reply paid envelope in which to return it. Employees were asked to give their opinions about their experiences of change within the department. The questionnaire included a supportive cover letter from the CEO of the Department, in which confidentiality of responses was assured.

In total, 877 completed questionnaires were received - a $68.4 \%$ response rate. A higher response rate in Study 2 was obtained using the support of management in the organization to organize survey completion sessions in specified locations. In addition, compared to the hospital, which was highly diverse in its divisions and functional specializations, the organization was smaller in staff numbers, there were fewer divisional structures to negotiate in gaining support for the research, and overall the organization was better organized in its ability to manage and support a survey. The sample was $47 \%$ male and $53 \%$ female. Ages ranged from under 20 years to over 50 years, and 26-30 years was the most frequently selected category. Over half the participants had worked in the department for at least four years and the majority were permanent full time workers (72\%). Occupational categories represented were: Direct Client Contact (21\%), Administrative $(20 \%)$, Management (15\%), Technical/Professional (11\%), Trade Staff $(6 \%)$, Policy/Planning (6\%), Secretarial (5\%), Project Work (11\%), and Other $(5 \%)$. As in Study 1, the sample was representative of the organization's entire workforce in relation to gender and occupational categories.

Measures. Participants provided background information on their gender, age, length of service, length of time in current position, and employment status (e.g., casual, full time, part time, contract, temporary). They selected one of nine occupational categories (e.g., administrative, management, policy/planning).

As in Study 1, three climate dimensions were measured. Again, exploratory interviews revealed a dimension of climate salient to employees in this organization. The role that leadership played in the management of change, especially the way leaders communicated their vision for the organization, was considered particularly important. It was generally felt that change needed to be managed by leaders who were seen as positive and who cared about people and recognized the efforts of staff. These comments related to the concept of leader vision, defined as leader behaviours that envision the future, create an ideal and unique image of what the organization can become, and get people to see exciting possibilities for 
the future (Kouzes \& Posner, 1993). Martin (1998) argued that visionary leaders instil trust, an important quality during the management of change. Hence, leader vision was measured with six items taken from Kouzes and Posner's Leadership Practices Inventory (e.g., "Senior staff show excitement about future possibilities"; $1=$ "strongly disagree" to $6=$ "strongly agree"). In relation to the stakeholder dimension, employees in this organization also highlighted the importance of managing change with a focus on customer satisfaction. Customer service was measured with seven items that assessed the perceived level of client satisfaction in the department (e.g., "We achieve high levels of client satisfaction"; 1 = "strongly disagree" to $6=$ "strongly agree"). These items were developed for use in the present research in conjunction with staff of the department and although no previous reliability data was available, the measure demonstrated good reliability as shown in Table 3. The third climate dimension, supervisor support, was measured using the same items described in Study 1.

The change appraisal measures of perceived change-related stress, change control, and change self-efficacy were the same as those described in the method of Study 1. The wording of the change stress item format was slightly modified to suit the organizational context (e.g., "Please rate your views about the nature of on-going changes": 1 = "not at all stressful" to $6=$ "extremely stressful"; $1=$ "not at all upsetting" to $6=$ "extremely upsetting"). In addition, the change control scale was modified slightly by the addition of two items in an attempt to increase its reliability. These items were adapted from Bordia et al. (2000) (e.g., "I feel I can influence the nature of change in my work unit"; $1=$ "strongly disagree" to $5=$ "strongly agree").

Employee adjustment during organizational change was measured as organizational commitment. Organizational commitment was assessed with five items (Mowday, Steers, \& Porter, 1979). The scale assesses generalized levels of commitment (e.g., "What happens in the department is really important to me"; 1 = "strongly disagree" to $5=$ "strongly agree"). One item was reverse scored: "I don't care what happens to the department as long as I get my pay". As organizational commitment is a major predictor of absenteeism and turnover intentions, these two additional variables were included in the model as outcomes of adjustment. Turnover intentions were measured with six items (Fried \& Teigs, 1995; Meyer, Allen, \& Smith, 1993) (e.g., "I am planning to search for a new job within the next 12 months"; $1=$ "strongly disagree" to $7=$ "strongly agree"). A measure of selfreported absenteeism was obtained using the procedure outlined by Parker and Kulik (1995). Participants were asked to estimate the number of days they had been absent due to reasons other than physical ill-health or leave entitlements. Participants were asked "How many days in the past 6 months have you been absent from work due to work-related reasons" (e.g., feeling 
depressed or stressed, emotionally run down, taking a "sickie", unfair workload, difficult work relationships). This measure was conceptualized as a proxy for the subset of days absent where employees are not physically ill. It is argued that this type of absenteeism is often related to aspects of psychological climate and is thus more preventable. Although the reliability and validity of a self-reported measure of absenteeism may seem questionable, the reality is that many organizations resist providing records-based data and, hence, a great number of studies have used selfreport measures to assess absenteeism (Johns, 1994). In addition, self-report measures provide a means of establishing the level of absenteeism that is voluntary (not due to illness).

Essentially, the same theoretical model of employee adjustment during organizational change tested in Study 1 was tested in Study 2. However, the climate variables were modified in relation to the organizational context as described above. In addition, to expand the range of variables examined as outcomes of the cognitive-phenomenological model, employee adjustment was measured with different indicators. The model tested in Study 2 predicted that employees with more positive perceptions of the psychological climate (leader vision, customer service, and levels of social support from their direct supervisor) would report more positive change appraisals (lower change stress and higher change control and self-efficacy), and higher levels of adjustment (organizational commitment). In addition, it was expected that the effects of climate-based coping resources upon organizational commitment would be mediated by how positively employees appraised the changes (perceived change stress, self-efficacy, and control). As the literature suggests that commitment is a major predictor of absenteeism and turnover intentions (Bennett \& Durkin, 2000; Lease, 1998), the model tested specified that the effects of the exogenous variables on absenteeism and turnover intentions would be mediated by organizational commitment.

\section{RESULTS}

\section{Data screening}

Data screening for respondent errors and omissions was conducted prior to analysis. In Study 1, missing values analyses revealed that the missing data ranged from $0.6 \%$ to $3.1 \%$, and in Study 2 missing data for scaled items ranged from $0.6 \%$ to $5.5 \%$. Structural equation analyses are unable to deal with any missing data and are considered more robust with larger sample sizes. To retain as many cases as possible, missing values were replaced with the linear trend for that point (the existing series is regressed on an index variable scaled 1 to $n$ and missing values are replaced with their predicted 
values). The data were analysed using the maximum likelihood procedure (Bentler \& Hu, 1995). Diagnostic procedures conducted on the data revealed that multivariate kurtosis was not marked in either sample, apart from the absenteeism variable in Study 2. The treatment of this variable is described below.

In Study 2 data, the distribution for the number of days absent due to work-related reasons was markedly skewed (skew $=14.70, S E=.085$ ). This common problem is due to the number of staff who report zero days absent (Hemmingway \& Smith, 1999). Even with square root and logarithmic transformations, the distribution did not approach normality, meaning that the assumptions for maximum likelihood procedure would be violated. These data were recoded into a dichotomous variable $(0=$ not absent, $1=$ absent) so that the relationship between the model variables and whether or not employees reported any absence due to work-related reasons could be estimated. However, readers should note that Kline (1998) and West, Finch, and Curran (1995) have argued that SEM estimates involving dichotomous variables are admissible but should be interpreted with caution.

\section{Data analysis}

Measurement models. Confirmatory factor analysis (see Anderson \& Gerbing, 1988) was used to test the adequacy of the measurement models. Separate models were estimated for each study. The items used to measure each of the theoretical constructs were used as indicators of latent variables. Factor variances were set to one in order to identify the model and a range of model fit and modification indices were computed. The pattern of results from the test of the a priori measurement models indicated that both models showed reasonably good fit to the data (see Table 1) but as the CFI was approaching but not exceeding the recommended cut-off of .95 in both cases, the models were improved with some minor respecification. As it is often difficult to obtain adequate fit for models with large numbers of indicators (Kline, 1998), a procedure for reducing the number of indicators was employed. Anderson and Gerbing (1988) proposed that deleting problem indicators is the preferred solution for improving the fit of measurement models.

Inspection of the standardized correlations among residuals and the Lagrange multiplier modification indices revealed that both models could be improved by dropping some of the items which showed evidence of multiple factor loadings. Kline (1998) has noted that some researchers allow indicators to load on more than one factor. The present analyses applied the more conservative principle of unidimensional measurement and did not 
TABLE 1

Goodness of fit statistics

\begin{tabular}{lccccc}
\hline Model & $\chi^{2}(d f)$ & $\chi^{2} / d f$ & $C F I$ & RMSEA & $\chi^{2 \text { diff }}$ \\
\hline Study 1 & & & & & \\
$\quad$ a priori measurement model & $2054(540) * * *$ & 3.8 & .89 & .06 & \\
$\quad$ Modified measurement model & $499(279) * * *$ & 1.84 & .97 & .03 & \\
One-factor model & $4548(275) * * *$ & 16.5 & .46 & .14 & $4049(4) * * *$ \\
a priori structural model & $537(275) * * *$ & 1.95 & .97 & .04 & \\
Direct effects model & $1219(287) * * *$ & 4.25 & .88 & .07 & $680(5) * * *$ \\
Fully mediated model & $1135(284) * * *$ & 4.0 & .89 & .06 & $596(2) * * *$ \\
Study 2 & & & & & \\
a priori measurement model & $3210(840) * * *$ & 3.82 & .90 & .06 & \\
Modified measurement model & $688(296) * * *$ & 2.32 & .97 & .04 & \\
One-factor model & $8337(324) * * *$ & 25.73 & .45 & .17 & $7649(28) * * *$ \\
$\quad$ a priori structural model & $869(334) * * *$ & 2.61 & .96 & .04 & \\
$\quad$ Direct effects model & $1308(330) * * *$ & 3.96 & .93 & .06 & $439(4) * * *$ \\
Fully mediated model & $956(334) * * *$ & 2.86 & .95 & .05 & $87(0) * * *$ \\
\hline
\end{tabular}

$* * * p<.001$.

make any respecifications that allowed items to load on multiple factors. In addition, factors with only three items were not respecified, as a minimum of three indicators per latent variable was required for model identification. Substantive considerations regarding an indicator's contribution to the content validity of each of the latent constructs were also taken into account. Indicators with large correlated residuals and/or highly significant cross-loadings on other factors were deleted. In Study 1, nine of the original thirty-five items were dropped from the model. In Study 2, 18 of the original 45 items were dropped from the model. However, constructs still retained three to four indicators, ${ }^{2}$ which is standard for CFA models with multiple factors (Bollen, 1989). The modified measurement models yielded an improved pattern of results in terms of the goodness of fit indices (see Table 1).

The correlations between the latent variables in both models were all within a low to moderate range, indicating good discriminant validity (Kline, 1988). Cronbach's alpha coefficients were computed for items used in the final measurement models and all inter-item correlations demonstrated satisfactory to high levels of reliability and good convergent validity (Kline, 1988). Tables 2 and 3 present the means, standard deviations, intercorrelations, and internal consistency alphas for the latent variables in each study.

\footnotetext{
${ }^{2}$ Tables detailing the item content, standardized path co-efficients and $r^{2}$ values for the confirmatory factor models for each of the studies are available upon request.
} 

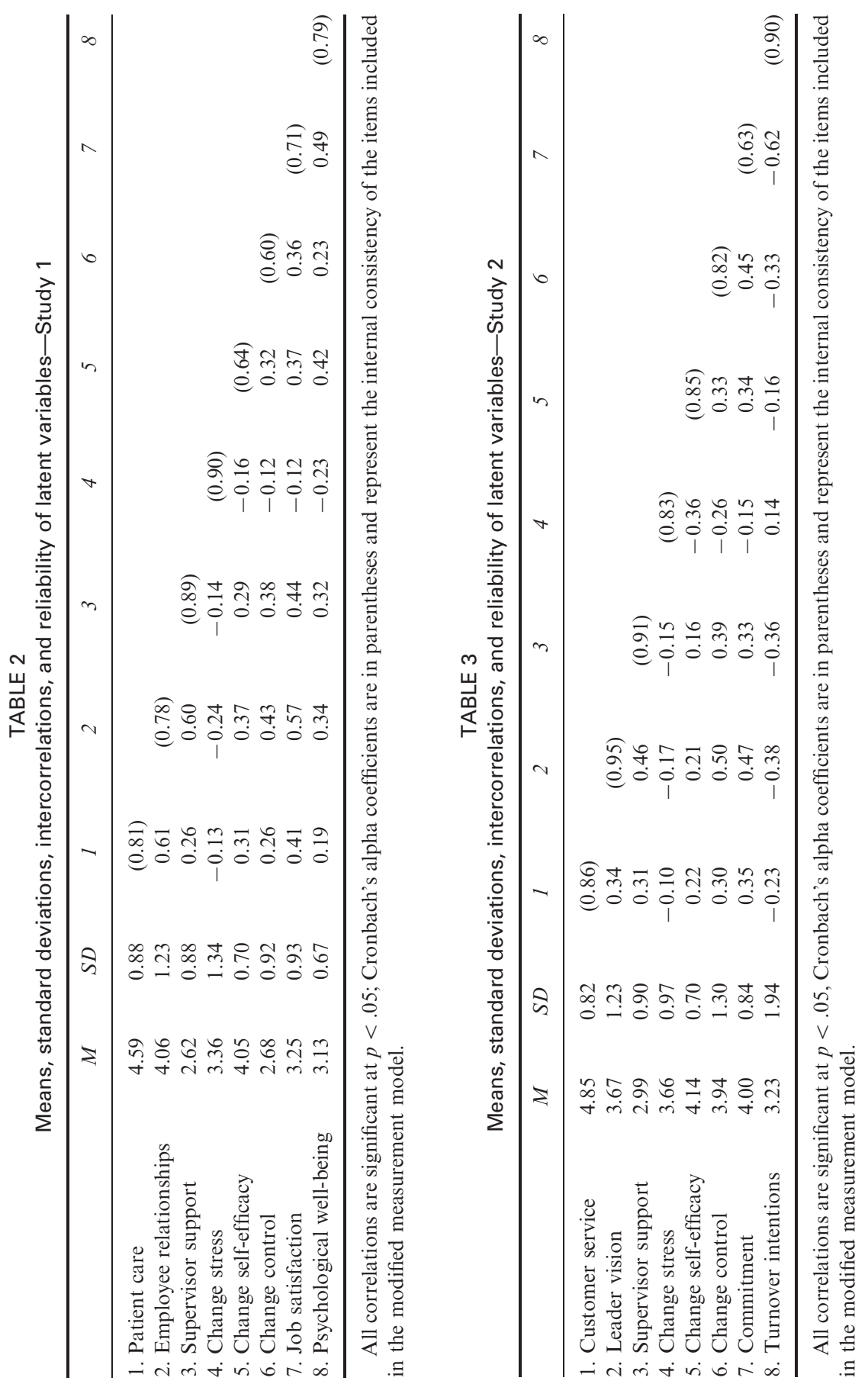
Finally, it is also important to note that none of the measurement error terms were significantly correlated.

A one-factor or baseline model did not fit the data well in either study and had large and significant chi-square differences when compared with the eight-factor measurement models tested in the CFA process described above (see Table 1). It has been suggested that such results provide an indication that common method variance did not pose a substantial threat to the validity of the measurement models (Harris \& Mossholder, 1996). This procedure assumes that if method variance is largely responsible for the covariation among the measures, a single (method) factor model should fit the data well. This step was taken in both models presented in the present research in order to discount the presence of severe common method variance.

Structural models. Structural equation modelling (using version $5.7 \mathrm{~b}$ of the EQS program; Bentler, 1989) was used to test the utility of the theoretical models proposed in the present research (see Figures 2 and 3). The pattern of results from the test of the a priori models suggested that the models were indeed a good fit to the data (see Table 1). In Study 1, 14 of the 21 predicted paths were significant at $p<.001$ level (see Figure 2). The nonsignificant paths between latent variables were: patient care and change

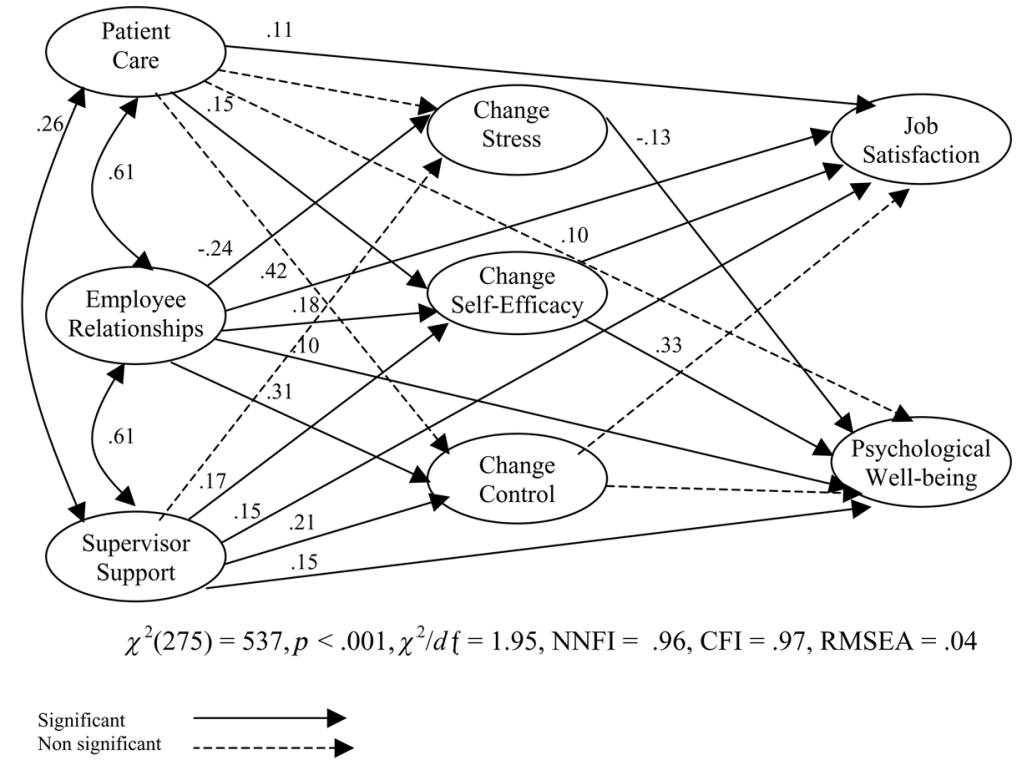

Figure 2. Final structural model-Study 1. 


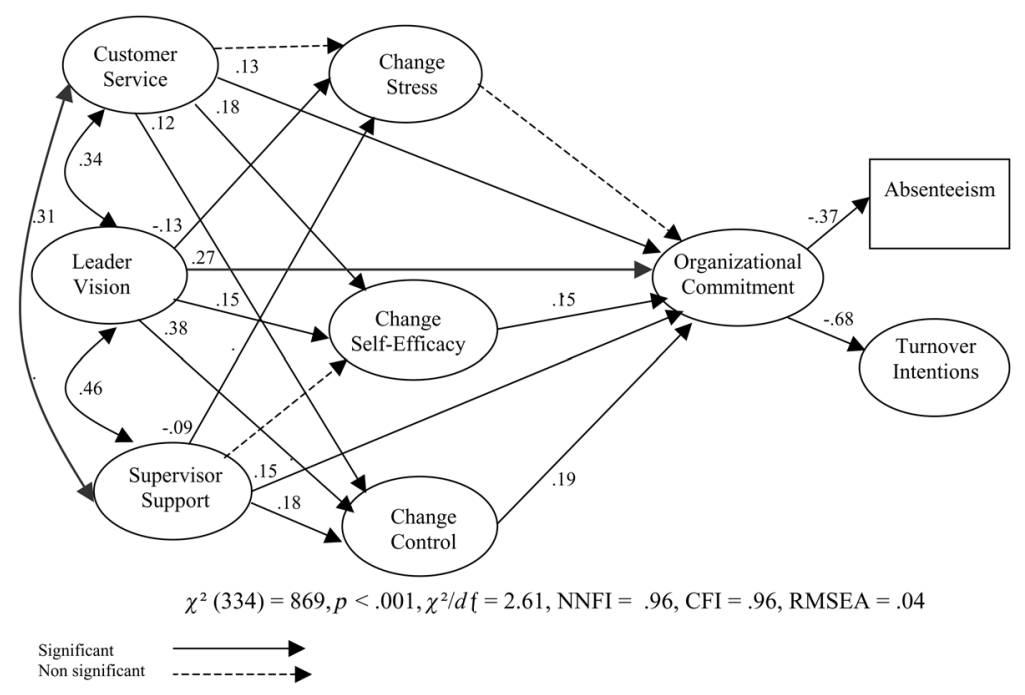

Figure 3. Final structural model-Study 2.

stress $\left(\chi^{2}=0.08, p=.78\right)$, patient care and change control $\left(\chi^{2}=0.40\right.$, $p=.53)$, patient care and well-being $\left(\chi^{2}=0.76, p=.38\right)$, social support and change stress $\left(\chi^{2}=0.04, p=.84\right)$, change stress and job satisfaction $\left(\chi^{2}=0.33, p=.57\right)$, change control and job satisfaction $\left(\chi^{2}=0.49\right.$, $p=.47)$, and change control and well-being $\left(\chi^{2}=0.16, p=.69\right)$, and employee relationships and well-being showed a trend towards significance $\left(\chi^{2}=3.04, p=.08\right)$. In terms of the endogenous variables, the final model explained $40 \%$ of the variance in job satisfaction and $26 \%$ of the variance in psychological well-being.

The results of the model tested in Study 1 demonstrated partial support for Hypothesis 1 as six of the nine predicted paths between psychological climate and change appraisal variables were significant. Hypothesis 2 was also partially supported as three of the six predicted paths between change appraisals and the organizational commitment were significant. Hypothesis 3 was partially supported as five of the six predicted paths between psychological climate variables and adjustment indicators were significant. Tests of indirect effects provided partial, but weaker support for Hypothesis 4 as the effects of the climate variables on the adjustment indicators were significantly mediated by self-efficacy for all three climate variables and the effect of employee relationships on psychological well-being was mediated by change stress.

In Study 2, 14 of the 17 specified paths between the latent variables were significant at the $p<.001$ level (see Figure 3). The nonsignificant paths 
included those between change stress and commitment $\left(\chi^{2}=0.01, p=.928\right)$, customer service and change stress $\left(\chi^{2}=1.03, p=.30\right)$, and supervisor social support and change self-efficacy $\left(\chi^{2}=1.32, p=.25\right)$. The final model explained $38 \%$ of the variance in organizational commitment and $46 \%$ of the variance in turnover intentions. As absenteeism was a dichotomous variable, the proportion of variance was not estimated.

The results of the model tested in Study 2 demonstrated partial support for Hypothesis 1 as seven of the nine predicted paths between psychological climate and change appraisal variables were significant. Hypothesis 2 was also partially supported as two of the three predicted paths between change appraisals and the adjustment indicators were significant. Hypothesis 3 was fully supported as all of the predicted paths between psychological climate variables and organizational commitment were significant. Again, examination of indirect effects showed partial, but weaker support for Hypothesis 4 as the effects of the climate variables on the adjustment indicators were significantly mediated by change control and change self-efficacy.

Alternative (or nested) models that could be proposed to account for the relations among the variables were also tested. There was evidence that the final structural models presented above (hybrid models which contained both direct and mediated paths) compared favourably with fully mediated models and models predicting direct effects only. Chi-square difference tests revealed that the differences between each of the alternative models and the final models were significant (see Table 1). These results suggest that the final structural models presented in Figures 2 and 3 best represent the relationships found in the data.

\section{DISCUSSION}

General support for the proposed theoretical model of employee adjustment during organizational change was found across both studies. The dimensions of psychological climate measured in the present research were conceptualized as coping resources that would be associated with positive appraisals about organizational change and in turn, enhanced levels of employee adjustment. The results of the present research supported the proposition of Eby et al. (2000) that employee perceptions of change are positively shaped by their perceptions of the work environment, and that employee cognitive and affective responses to change are important predictors of a range of adjustment indicators (Roney \& Cooper, 1997; Terry et al., 1996; Wanberg \& Banas, 2000).

Across both studies, psychological climate was measured using organization-specific, generic, and stakeholder dimensions. Interestingly, organization-specific elements of climate were generally stronger predictors of change appraisals and adjustment indicators. The measure of employee relation- 
ships was included as a climate factor in the hospital context in Study 1 as a result of exploratory interviews. It proved to be a powerful explanatory variable in the model tested. Likewise, the measure of leader vision was included in the public sector context because it was identified by employees as a salient climate factor, and was a stronger predictor of both appraisal and adjustment than the other climate variables. These results support the idea that researchers need to include measures in climate research that are more organization and situation specific (Dewe \& O'Driscoll, 1999; Hart \& Wearing, 1995). However, it should be noted that this does limit the potential for generalization and meta-analysis.

In terms of an extended version of the cognitive phenomenological framework, the results for the models tested demonstrate the utility of including psychological climate, and extends the concept of coping resources beyond the individual differences approach that usually is the focus of stress and coping research. The findings of the present research also provide empirical support for several more specific relations among the variables of interest. In Study 1, positive employee relationships had a strong main effect on job satisfaction and showed a trend towards a significant effect on psychological well-being. This variable also demonstrated a consistently strong association with all of the appraisal measures. Those who rated the social climate more positively also felt less distressed by the changes and more confident and in control of how the change would affect them. These findings are in accordance with the broader literature on the positive effects of a cohesive social climate (Harris \& Mossholder, 1996).

In Study 2, employees who perceived that their leaders exhibited an enthusiastic vision for the organization reported more positive change appraisals and higher levels of commitment. Leader vision had a particularly strong relationship with employee perceptions of change control. Perhaps this is because leaders who communicate effectively give employees a sense that they can contribute to the changes. Kotter (1995) stated that visionary leadership contributes to individual judgements about change by creating excitement and enthusiasm about future possibilities and by modelling appropriate behaviour in the changing organization. Studies of effective transformational leaders show how important it is for them to have a clear vision of the destiny of the organization and that they can use this vision to gain the support and confidence of key employees. These actions help to build stability during the change and enhance employee commitment to the organization (Covin \& Kilmann, 1990).

Across both studies, supervisor support was a generic climate-based resource that was associated with change appraisal and adjustment. Evidence that support-adjustment links are direct (Cohen \& Wills, 1985) was seen across the two studies in the main effects of supervisor support on the adjustment indicators and change appraisals. However, evidence that 
support-adjustment links are mediated by situational appraisals (Lazarus, 1990; Lazarus \& Folkman, 1984; Terry et al., 1996) was also seen in the indirect effects found in both models (support $\rightarrow$ control $\rightarrow$ commitment; support $\rightarrow$ self-efficacy $\rightarrow$ job satisfaction; support $\rightarrow$ self-efficacy $\rightarrow$ wellbeing). As noted by Larkin and Larkin (1994), communication with immediate supervisors is especially important during organizational change as supervisors have considerable power to influence and change employee behaviour. Supervisors provide information relevant to positive selfevaluation and social comparison - a potential path to improving change self-efficacy. In addition, they may be able to alter stressful aspects of change in response to employees who express their concerns, thereby improving employee perceptions of change control (House, 1981; Terry et al., 1996).

The other element of climate assessed in both studies related to employees' perceptions of their organization's level of orientation towards its major clients. These measures reflected the stakeholder approach recommended by Burke et al. (2002), and were measured according to the specific stakeholders and elements of service relevant in each organization. In Study 1, positive perceptions of the quality of patient care were directly linked to both increased change self-efficacy and job satisfaction. In Study 2, positive beliefs about the organization's ability to provide good customer service was associated with increased change self-efficacy and change control and was directly linked to organizational commitment (and, in turn, to absenteeism and turnover intentions). Service orientation or quality emphasis in organizational climates is generally associated with employee satisfaction and high levels of organizational performance (Schnieder, 2000). During change, the desire to satisfy clients is thought to provide a level of continuity, direction, and control (Harber, Ashkanasy, \& Callan, 1997). However, the hypothesized link between the stakeholder factor (customer service/quality of patient care) and change stress was not confirmed in either study, suggesting that the other climate factors have a more significant association with perceptions of stress.

In terms of the effects of change appraisals on adjustment indicators, Study 1 confirmed that perceptions about organizational change were associated with employee well-being (Mack et al., 1998; Roney \& Cooper, 1997; Schabracq \& Cooper, 1998). However, no significant links were found between perceptions of change-related stress and job satisfaction in Study 1 or organizational commitment in Study 2. This may be a function of the more affective nature of the change stress measure, which could be expected to correlate better with psychological well-being than the other organizationally focused outcomes.

Consistent in both studies was the role of change self-efficacy as an important mediator between the climate variables and adjustment indicators. This finding supports the increasing prominence of self-efficacy in the 
literature on psychological adjustment in a wide range of contexts (Jerusalem \& Mittag, 1995). A person's efficacy expectancy about their ability to perform new behaviours is an important determinant of adjustment, exerting a strong influence on an individual's assessment of a situation as either challenging or threatening (Bandura, 1982; Judge et al., 1999).

However, change control, although predicted by two of the climate factors, did not link to either of the adjustment indicators in Study 1. A possible reason that these relationships were not stronger relates to the measurement of change control in Study 1. It should be noted that the measure of control exhibited a low but acceptable level of reliability, $\alpha=.60$ (Carmines \& Zeller, 1979). This measure was improved in Study 2, and achieved a higher level of reliability $(\alpha=.82)$. The improved measure was a significant mediator between the climate factors and organizational commitment. Control was also indirectly associated with absenteeism and turnover intentions, via its impact on commitment. Having control over changing situations has been previously associated with less negative reactions to organizational changes (Lau \& Woodman, 1995) and improved adjustment to work stress generally (Karasek, 1979).

It should be noted that across both studies, the mediation effects that were significant, although not particularly strong, were generally comparable with those reported by Terry et al. (1996). The direct effects of climate on adjustment were the strongest observed in both studies. These results suggested that although organizational change does affect a range of employee and organizational outcomes, the more stable elements of the work environment continue to explain a large proportion of the variance in these variables. These findings support mounting research evidence that climate is a key predictor of work attitudes such as job satisfaction, organizational commitment, and turnover intentions (Parker et al., 2003; Schneider et al., 2000). The direct links between organizational commitment and both absenteeism and turnover intentions in Study 2 were also quite strong, consistent with recent reviews of the literature (Bennett \& Durkin, 2000; Lease, 1998). These findings suggest that the development of a positive psychological climate may not only improve employee appraisals of change, but that this process could also have an impact on important cost-related organizational outcomes. However, it needs to be acknowledged that the strong direct effects of climate on adjustment may also be influenced by the level at which the constructs were measured. Climate and work attitudes are global measures, whereas change appraisals are more micro-level, in that they measure individuals' self-assessments of their reactions to the specific work event of organizational change.

The results of the present research constitute an important contribution to the change management literature. Stress management training, which 
covers cognitive reappraisal processes, counselling, and relaxation techniques, is often the sole form of intervention offered to employees during organizational change. It has been noted that this may not be the most effective strategy and that efforts would be better directed towards the promotion of a healthy and supportive work environment (Reynolds \& Shapiro, 1991). In particular, the results suggested that diagnostic processes that determine the salient elements of the climate in an organization should be undertaken and that efforts to strengthen and develop these elements may result in both improved employee adjustment and enhanced employee perceptions of change programs. Organization development efforts are increasingly focused on the design of organizational climate as a means of improving the work attitudes that have been associated with improving employee motivation, performance, retention and absenteeism (Lease, 1998; Parker et al., 2003). Whilst such development is a worthwhile endeavour, the slow and difficult path to changing negative climates in organizations should not be underestimated (Gunnarson \& Niles-Jolly, 1996).

The key role of self-efficacy in predicting all of the adjustment indicators suggests that increasing change self-efficacy could be a useful secondary-level intervention strategy. Resistance to change can stem from fear of being unable to perform under new work arrangements. Training can address these fears directly by providing skills and indirectly by providing opportunities for peer support (Michela \& Burke, 2000). Alternatively, Orlikowski (1996, cited in Schabracq \& Cooper, 1998) advocated a major paradigm shift toward the implementation of situated change, which is described as ongoing incremental adjustment and adaptation, as opposed to planned or transformational change. An incremental approach to change is consistent with Bandura's concept of enactive mastery; the gradual accumulation of successively more complex skills. Such an approach would maximize feelings of self-efficacy and minimizes stress that results from the realization that established (automatic) responses are no longer effective in a new setting. These results also suggest that increasing situational control could also have some impact on adjustment during change. As seen in the wider literature, understanding, prediction, and control are powerful antidotes to workrelated stress (Sutton \& Kahn, 1986). Organizations implementing change are urged to involve employees and use a participative approach to change management in order to increase their perceptions of situational control.

The major limitation of the present research was that all the analyses presented were based on a cross-sectional design. Hence, it is not possible to draw any inferences regarding causal relations among the variables. However, two procedures were used to address this concern and allow more confidence in the results. Firstly, the results of Harman's Single Factor test (see Harris \& Mossholder, 1996) provided evidence that common method variance was not a major threat to the validity of the results. 
Secondly, the use of a quasi-replication approach provided some evidence of consistent relationships among similar or identical variables that were of similar magnitude and direction across two independent samples. An additional limitation related to the necessity of dichotomizing the absenteeism variable. As noted earlier, SEM estimates involving dichotomous variables are admissible but should be interpreted with caution by (Kline, 1998; West et al., 1995).

The results reported here should guide the design of future research. The effects of organization-specific climate interventions on employee adjustment during change need to be confirmed quasiexperimentally using longitudinal designs. In addition, the theoretical model described here must be further tested. Model variables could also be linked to sources of data not reliant on self-report methods. The application of other alternative methodologies, such as the within- and between-subjects and multilevel techniques that allow the level agreement of participants about climate variables to be established, could also be fruitful (Burke et al., 2002).

\section{REFERENCES}

Anderson, J. G., \& Gerbing, D. W. (1988). Structural equation modeling in practice: A review and recommended two-step approach. Psychological Bulletin, 103, 411-423.

Armenakis, A. A., \& Bedeian, A. G. (1999). Organizational change: A review of theory and research in the 1990's. Journal of Management, 25, 293-315.

Ashford, S. J. (1988). Individual strategies for coping with stress during organizational transitions. Journal of Applied Behavioural Science, 24, 19-36.

Averill, J. R. (1973). Personal control over aversive stimuli and its relationship to stress. Psychological Bulletin, 80, 286-303.

Bandura, A. (1982). Self-efficacy mechanisms in human agency. American Psychologist, 37, $122-147$.

Bandura, A. (1986). Social foundations of thought and action: A social cognitive theory. Englewood Cliffs, NJ: Prentice Hall.

Bennett, H., \& Durkin, M. (2000). The effects of organizational change on employee psychological attachment: An exploratory study. Journal of Managerial Psychology, 15, $126-147$.

Bentler, P. M., \& Hu, L. (1995). EQS structural equations program manual. Los Angeles: BMDP Statistical Software.

Bollen, K. A. (1989). Structural equations with latent variables. New York: Wiley.

Bordia, P., Hunt, E., Paulsen, N., Tourish, D., \& DiFonzo, N. (2000). Communication and uncertainty during organisational change: It's all about control. Unpublished manuscript.

Burke, M. J., Borucki, C. C., \& Kaufman, J. D. (2002). Contemporary perspectives on the study of psychological climate: A commentary. European Journal of Work and Organizational Psychology, 11, 325-340.

Burke, R. J. (1993). Organizational level interventions to reduce occupational stressors. Work and Stress, 7, 77-87.

Caplan, R. D., Cobb, S., French, J. R. P., van Harrison, R. V., \& Pinneau, Jr., S. R. (1975). Job demands and worker health. Washington, DC: US Department of Health, Education and Welfare. 
Carmines, E. G., \& Zeller, R. A. (1979). Reliability and validity assessment. Beverly Hills, CA: Sage Publications.

Cohen, S., \& Wills, T. A. (1985). Stress, social support, and the buffering hypothesis. Psychological Bulletin, 98, 310-357.

Covin, T. J., \& Kilmann, R. H. (1990). Participant perceptions of positive and negative influences on large-scale change. Group and Organization Studies, 15, 233-248.

Dewe, P., \& O'Driscoll, M. (1999). Stress management interventions: What do managers actually $d o$ ? Paper presented at the Annual Conference of Industrial and Organisational Psychology, Brisbane, Australia.

Eby, L. T., Adams, D. M., Russell, J. E. A., \& Gaby, S. H. (2000). Perceptions of organizational readiness for change: Factors related to employees' reactions to the implementation of team based selling. Human Relations, 53, 419-442.

Fogarty, G. J., Machin, M. A., Albion, M. J., Sutherland, L. F., Lalor, G. I., \& Revitt, S. (1999). Predicting occupational strain and job satisfaction: The role of stress, coping, personality and affectivity variables. Journal of Vocational Behaviour, 54, 429-452.

Folkman, S. (1984). Personal control and stress and coping processes: A theoretical analysis. Journal of Personality and Social Psychology, 46, 839-852.

Fried, Y., \& Tiegs, R. B. (1995). Supervisors' role conflict and role ambiguity differential relations with performance ratings of subordinates and the moderating effect of screening ability. Journal of Applied Psychology, 80, 282-291.

Ganster, D. J. (1985). Exploring the role of control in occupational stress. Paper presented at NIOSH workshop on Occupational Stress Management, New Orleans, LA.

Glick, W. H. (1985). Conceptualising and measuring organizational and psychological climate: Pitfalls in multilevel research. Academy of Management Review, 10, 601-616.

Goldberg, D. P. (1972). The detection of psychiatric illnesses by questionnaire. Oxford, UK: Oxford University Press.

Gunnarson, B. K., \& Niles-Jolly, K. (1996). Creating the climate and culture of success. Organizational Dynamics, 23, 17-30.

Harber, D. G., Ashkanasy, N. M., \& Callan, V. J. (1997). Implementing quality service in a public hospital setting: A path-analytical study of organizational antecedents of employee perceptions and outcomes. Public Productivity and Management Review, 21, 13-29.

Harris, S. G., \& Mossholder, K. W. (1996). The affective implications of perceived congruence with culture dimensions during organizational transformation. Journal of Management, 22, $527-547$.

Hart, P. M., \& Wearing, A. J. (1995). Occupational stress and well-being: A systematic approach to research, policy, and practice. In P. Cotton (Ed.), Psychological health in the workplace: Understanding and managing occupational stress. Melbourne, Australia: Australian Psychological Society.

Hemmingway, M. A., \& Smith, C. S. (1999). Organizational climate and occupational stressors as predictors of withdrawal behaviours and injuries in nurses. Journal of Occupational and Organizational Psychology, 72, 1-10.

House, J. S. (1981). Work stress and social support. Reading, MA: Addison-Wesley.

Jerusalem, M., \& Mittag, W. (1995). Self-efficacy in stressful life transitions. In A. Bandura (Ed.), Self-efficacy in changing societies (pp. 177-201). New York: Cambridge University Press.

Johns, G. (1994). How often were you absent? A review of the use of self-reported absence data. Journal of Applied Psychology, 79, 574-591.

Judge, T. A., Thoresen, C. J., Pucik, V., \& Welbourne, T. M. (1999). Managerial coping with organizational change: A dispositional perspective. Journal of Applied Psychology, 84, $107-$ 122.

Karasek R. A. (1979). Job demands, job decision latitude and mental strain: Implications for job redesign. Administrative Science Quarterly, 24, 285-307. 
Kline, R. B. (1998). Principles and practices of structural equation modelling. London: Guilford Press.

Kotter, J. (1995). Leading change: Why transformational efforts fail. Harvard Business Review, March-April, 59-67.

Kouzes, J. M., \& Posner, B. Z. (1993). Credibility: How leaders gain and lose it, why people demand it. San Francisco: Jossey-Bass Publishers.

Kumari, K., \& Sharma, S. (1990). Social support, organizational role stress and well being: A study of medicos. Psychological Studies, 35, 163-169.

Larkin, T. J., \& Larkin, S. (1994). Communicating change: How to win employee support for new business directions. New York: McGraw-Hill.

Lau, C., \& Woodman, R. W. (1995). Understanding organizational change: A schematic perspective. Academy of Management Journal, 38, 537-554.

Lazarus, R. S. (1990). Theory-based stress measurement. Psychological Inquiry, 1, 3 - 13.

Lazarus, R. S. (2000). Toward better research on stress and coping. American Psychologist, June, $665-673$.

Lazarus, R. S., \& Folkman, S. (1984). Stress, appraisal and coping. New York: Springer Publishing Company.

Lease, S. H. (1998). Annual review, 1993-1997: Work attitudes and outcomes. Journal of Vocational Behaviour, 53, 154-183.

Lokk, J., \& Arnetz, B. (1997). Psychophysiological concomitants of organizational change in health care personnel: Effects of a controlled intervention study. Psychotherapy and Psychosomatics, 66, 74-77.

Mack, D. A., Nelson, D. L., \& Quick, J. C. (1998). The stress of organizational change: A dynamic process model. Applied Psychology: An International Review, 47, 219-232.

Martin, M. (1998). Trust leadership. Journal of Leadership Studies, 5, 41-50.

McManus, S. E., Russell, J. E. A., Freeman, D. M., \& Rohricht, M. T. (1995, August). Factors related to employees' perceptions of organizational readiness for change. Paper presented at the annual meeting of the Academy of Management, Vancouver, BC, Canada.

Meyer, J. P., Allen, N. J., \& Smith, C. A. (1993). Commitment to organizations and occupations: Extension and test of a three-component conceptualization. Journal of Applied Psychology, 78, 538-551.

Michela, J. L., \& Burke, W. W. (2000). Organizational culture and climate in transformations for quality and innovation. In N. Ashkanasy, C. Widerom, \& M. Peterson (Eds.), Handbook of organizational culture and climate. Thousand Oaks, CA: Sage.

Michela, J. L., Lukaszwski, M. P., \& Allegrante, J. P. (1995). Organizational climate and work stress: A general framework applied to inner-city schoolteachers. In S. L. Sauter \& L. R. Murphy (Eds.), Organizational risk factors for job stress (pp. 61-80). Washington, DC: American Psychological Association.

Mowday, R. T., Steers, R. M., \& Porter, L. W. (1979). The measurement of organizational commitment. Journal of Vocational Behaviour, 14, 224-247.

Parker, C. P., Baltes, B. B., Young, S. A., Huff, J. W., Altmann, R. A., Lacost, H. A., \& Roberts, J. E. (2003). Relationships between psychological climate perceptions and work outcomes: A meta-analytic review. Journal of Organizational Behaviour, 24, 389-416.

Parker, P. A., \& Kulik, J. A. (1995). Burnout, self and supervisor-related job performance and absenteeism among nurses. Journal of Behavioural Medicine, 18, $581-599$.

Parks, K. A. (1990). Coping, negative affectivity and the work environment: Additive and interactive predictors of mental health. Journal of Applied Psychology, 75, 399-409.

Payne, R. L. (2000). Climate and culture: How close can they get? In N. Ashkanasy, C. Widerom, \& M. Peterson (Eds.), Handbook of organizational culture and climate. Thousand Oaks, CA: Sage. 
Pettigrew, A. (2000). Foreword. In N. M. Ashkanasy, C. P.M. Wilderom, \& M. F. Peterson (Eds.), Handbook of organizational culture and climate. Thousand Oaks, CA: Sage.

Pettigrew, A. M., Woodman, R. W., \& Cameron, K. S. (2001). Studying organizational change and development: Challenges for future research. Academy of Management Review, 44, $697-713$.

Przygodda, M., Arentz, K. P., Quast, H. H., \& Kleinbeck, W. (1997). Leadership style and absenteeism in organizations: A study of medical emergency personnel in a community medical emergency service. Zeitschrift fuer Arbeits und Organizationspsychologie, 35, 179186.

Reynolds, S., \& Briner, R. B. (1994). Stress management at work: With whom, for whom and to what ends? British Journal of Guidance and Counselling, 22, 75-89.

Reynolds, S., \& Shapiro, D. A. (1991). Stress reduction in transition: Conceptual problems in the design, implementation and evaluation of worksite stress management interventions. Human Relations, 44, 717-733.

Roney, A., \& Cooper, C. (1997). Professionals on workplace stress: The essential facts. Chichester, UK: John Wiley \& Sons.

Schabracq, M. J., \& Cooper, C. L. (1998). Toward a phenomenological framework for the study of work and organizational stress. Human Relations, 51, 625-648.

Schaubroeck, J., \& Merritt, E. E. (1997). Divergent effects of job control on coping with work stressors: The key role of self-efficacy. Academy of Management Journal, 40, 738 - 754.

Schein, E. H. (2000). Sense and nonsense about culture and climate. In N. Ashkanasy, C. P. M. Widerom, \& M. F. Peterson (Eds.), Handbook of organizational culture and climate. Thousand Oaks, CA: Sage.

Schneider, B. (2000). The psychological life of organizations. In N. M. Ashkanasy, C. P. M. Widerom, \& M. F. Peterson (Eds.), Handbook of organizational culture and climate. Thousand Oaks, CA: Sage.

Schneider, B., Bowen, D. E., Ehrhart, M. G., \& Holcombe, K. M. (2000). The climate for service: Evolution of a construct. In N. M. Ashkanasy, C. P. M. Widerom, \& M. F. Peterson (Eds.), Handbook of organizational culture and climate. Thousand Oaks, CA: Sage.

St. Amour, D. (2001). Successful organizational change: Effective management of people and cultural issues. Canadian Manager, Summer, 20-22.

Sutton, R. I., \& Kahn, R. L. (1986). Prediction, understanding and control as antidotes to organizational stress. In J. W. Lorsch (Ed.), Handbook of organizational behaviour. Englewood Cliffs, NJ: Prentice Hall.

Terry, D. J. (1991). Coping resources and situational appraisals as predictors of coping behaviour. Personality and Individual Differences, 12, 1031-1047.

Terry, D. J., Callan, V. J., \& Sartori, G. (1996). Employee adjustment to an organizational merger: Stress, coping and intergroup differences. Stress Medicine, 12, 105-122.

Terry, D. J., \& Jimmieson, N. L. (1999). Work control and employee well-being: A decade in review. In E. L. Cooper \& I. T. Robertson (Eds.), International review of industrial and organizational psychology (Vol. 14, pp. 95-148) New York: Wiley.

Thoits, P. A. (1986). Social support as coping assistance. Journal of Consulting and Clinical Psychology, 54, 416-423.

Wanberg, C. R., \& Banas, J. T. (2000). Predictors and outcomes of openness to change in a reorganizing workplace. Journal of Applied Psychology, 85, 132-142.

West, S. G., Finch, J. F., \& Curran, P. J. (1995). Structural equation models with non-normal variables: Problems and remedies. In R. H. Hoyle (Ed.), Structural equation modelling: Concepts, issues, and applications. Thousand Oaks, CA: Sage. 